\title{
Representações sociais sobre a Aids entre jovens rurais e urbanos de Minas Gerais
}

\section{Social Representations of Aids among rural and urban youngsters on the state of Minas Gerais}

\author{
Margarete Moreira Coutinho e Silva ${ }^{1}$; Sheila Maria Doula²
}

\begin{abstract}
Resumo
$\mathrm{O}$ artigo analisa as representações de jovens rurais e urbanos sobre a Aids, verificando se a intensificação da relação cidade/campo, com a crescente facilidade dos acessos entre ambos os espaços, resulta em homogeneização simbólica sobre a doença. Esta aproximação, principalmente facilitada pelo avanço da tecnologia e de trânsito físico, vem proporcionando aos jovens rurais a recepção de informações que os colocam em consonância de atitudes e vulnerabilidades em relação aos jovens urbanos. Participaram da pesquisa 131 jovens estudantes do Curso Técnico em Agropecuária do IF Sudeste de Minas Gerais - Campus Barbacena, dentre eles 40 residentes na zona rural. Aponta, o estudo, para o fato de que os jovens pressupõem ter conhecimento sobre a Aids, porém as respostas dadas aos questionários denunciam a alta condição de vulnerabilidade à doença. A análise, orientada pelas teorias das representações sociais, permite constatar que estereótipos sobre as doenças permanecem incutidos no campo simbólico, também colaborando para a convergência de opiniões e condutas.
\end{abstract}

Palavras-chaves: AIDS. Representações sociais. Juventude.

\begin{abstract}
This article analyzes the representations of rural and urban youngsters on the subject of aids. It aims to verify if the intensification of the interaction between country and city that provides increasing access to both spaces results in a symbolic homogeneity on some aspects of the disease. The technological progress and the physical mobility advance promote this approach, which provides information to rural youngsters that put them in situations of consonance of attitudes and vulnerabilities in comparison with the urban youngsters. The research used data based on the sample of 131 students from the Curso Técnico em Agropecuária of the federal institute IF Sudeste de Minas Gerais - Campus Barbacena amongst whom 40 residents in rural areas. The results reveal that the youngsters assume they are aware of aids, but their responses to the questionnaire betray a state of high vulnerability to the disease. The analysis is guided by the social representation theories and shows that stereotypes about diseases remain instilled in the symbolic countryside, collaborating to the convergence of opinions and conducts.
\end{abstract}

keywords: AIDS. Social representations. Youth.

\footnotetext{
${ }^{1}$ Mestre em Extensão Rural pela Universidade Federal de Viçosa. Enfermeira Responsável técnica no setor de Enfermagem do Instituto Federal do Sudeste de Minas Gerais - Câmpus Barbacena. Enfermeira no Centro de Atenção Psicossocial da Prefeitura Municipal de Conselheiro Lafaiete - MG. E-mail: margaretecoutinho@ifsudestemg.edu.br

${ }^{2}$ Doutora em Antropologia Social pela Universidade de São Paulo. Professora Associada II da Universidade Federal de Viçosa. E-mail: sheila@ufv.br
} 


\section{Introdução}

No final do século XX, quando aos olhares da biomedicina pareciam controlados as causas e os meios de tratamento das doenças sexualmente transmissíveis, a Aids surgia como doença enigmática e incurável, dilacerando vidas, alastrando-se rapidamente e impondo-se como um desafio a ser compreendido e vencido. A Aids trouxe consigo novos discursos e posturas a respeito dos comportamentos, sobretudo aqueles relacionados à sexualidade e às relações íntimas. Noções de perigo e contágio, disseminadas principalmente pelo mistério que a envolvia, assim como o perfil social das primeiras vítimas, fizeram com que as representações sobre a doença assumissem um conteúdo preconceituoso, fato que pode ser observado ainda hoje nos discursos que se reproduzem em todos os segmentos das sociedades, mesmo depois de identificados os mecanismos de prevenção e instituído o tratamento, ainda que não se tenha uma perspectiva de cura.

Evidências científicas indicam que a idade da iniciação sexual tem reduzido e o número de casos de Aids na população jovem é crescente, sendo que a via de transmissão sexual responde pela maior parte dos casos registrados, seguida da via sanguínea, geralmente decorrente do uso de drogas injetáveis. Também sugerem as pesquisas que os jovens estão vulneráveis ao risco da prática sexual ingênua e das fantasias das sensações efêmeras proporcionadas pela intensificação das relações e dos contatos íntimos "liquefeitos", característicos da pós-modernidade (BRASIL, 2006; BAUMAN, 2004; CAMARGO; FERRARI, 2009; SILVA, 2007; VIEIRA, 2004).

$\mathrm{O}$ artigo pretende analisar como os jovens têm percebido a Aids, focalizando as atribuições simbólicas relacionadas ao significado da doença e às condições de vulnerabilidade a que estão expostos, tendo-se como objetivo central a comparação entre as representações dos jovens de residência rural em relação aos jovens de residência urbana.
Tal perspectiva se justifica a partir das interações culturais rurais/urbanas que se desenvolvem em espaços juvenis de socialização como a escola e as novas tecnologias de comunicação, por exemplo, nos quais a fonte e a recepção de informações sobre a Aids podem se processar de forma mais ampla e homogeneizada.

Vários pesquisadores brasileiros vêm destacando, por um lado, a aceleração do movimento de estreitamento das distâncias físicas e culturais entre o rural e o urbano (CARNEIRO, 1998; SOBARZO, 2010; WANDERLEY, 2009) e, por outro, o processo de "interiorização" da Aids dado o aumento de possibilidades de adoção de novas práticas e estilos de vida superpostos, notadamente entre os jovens rurais. Estes jovens são marcados por tendências migratórias (SILVA, 2007) e constituem a parcela da população rural que obtém emprego nas atividades agrícolas sazonais ou nos serviços urbanos não especializados, num movimento pendular entre cidade e campo. Além de emprego, os jovens rurais intensificam o fluxo campo/cidade em busca de educação e lazer, aumentando, inclusive, as possibilidades de exposição a doenças consideradas pelo imaginário social como típicas das sociedades urbanas e industrializadas.

Da mesma forma, os jovens rurais dispõem atualmente de uma rede de ensino formal com conteúdo de cunho universalista, no qual se insere o tema transversal da sexualidade e das doenças sexualmente transmissíveis (DST). Também se pode afirmar que a juventude rural, em medidas variáveis de abrangência e eficácia, é beneficiária de políticas públicas que visam disseminar informações sobre as DST e a gravidez na adolescência, dois riscos que, ao lado da violência e do desemprego, reforçam a representação sobre a juventude brasileira contemporânea como problema social.

A partir dessas premissas, constituem-se como objetivos específicos neste artigo discutir como as informações relacionadas à prevenção e ao conhecimento das formas de contágio do HIV/Aids 
estão alcançando a juventude rural e identificar se a aproximação com o meio urbano afeta as representações dos jovens rurais sobre a vivência da sexualidade e as atitudes preventivas.

\section{Métodos}

Para fins deste estudo utilizamos uma abordagem qualitativa com base na Teoria das Representações Sociais. Trata-se de estudo do tipo descritivoexploratório por meio de corte transversal, no qual se aplicam os métodos da revisão bibliográfica, da análise documental e da coleta de dados através de aplicação de questionário.

O universo empírico escolhido foi o município de Barbacena - MG, mais precisamente o Instituto Federal de Educação, Ciência e Tecnologia do Sudeste de Minas Gerais - Campus Barbacena, e o público participante foi formado por jovens rurais e urbanos, estudantes do Curso Técnico em Agropecuária Integrado ao Ensino Médio dessa instituição.

Foi aplicado um questionário semiestruturado aos jovens da primeira série $B$, da segunda série $A$, da terceira série A e da quarta série única do curso Técnico em Agropecuária Integrado ao Ensino Médio do ano de 2012, perfazendo um total de 131 alunos. Destes, 91 alunos eram urbanos e 40 rurais. A classificação como rurais ou urbanos ocorreu a partir da autodeclaração em relação ao local de residência (rural ou urbano) como resposta a uma das questões e a identificação do nome da cidade (ou localidade) de residência como resposta a outra.

O questionário continha blocos formados por perguntas abertas, nas quais os alunos poderiam emitir opiniões, descrever situações ou elaborar associações de ideias. A análise de conteúdo foi realizada a partir de palavras chave ou núcleo de ideias principais que apareceram repetidas de forma regular entre todos os entrevistados. As palavras foram separadas em grupos de semelhanças de significado e posteriormente classificadas em oito categorias que se configuram como elementos da representação social sobre a Aids. A porcentagem de evocação foi calculada de acordo com o total de palavras evocadas por todos os jovens.

\section{Doenças e representações sociais}

Deschamps e Moliner (2009) destacam três tipos principais de representações: as icnográficas, que são as imagens, pinturas, desenhos ou fotografias de um objeto; as simbólicas, que são constituídas de sinais que descrevem as propriedades dos objetos, sendo necessário o domínio do código para compreendê-las; e, finalmente, as representações cognitivas, constituídas de imagens mentais e elementos simbólicos que permitem a comunicação a propósito de um objeto, e que "são partilhadas por uma sociedade num conjunto e relativas a aspectos bem gerais do mundo." (DESCHAMPS; MOLINER, 2009, p. 76-78).

O conceito de representações coletivas foi proposto por Durkheim para designar "um conjunto de saberes que são produzidos por uma sociedade em sua globalidade" e elaborados a partir de sistemas cognitivos de classificação e ordenamento da realidade social e coletiva. Para Durkheim os mitos, as religiões e a ciência são exemplos dos grandes sistemas que se alimentam desse processo classificatório e são coletivos por se tratarem de processos que necessitam da reunião de todas as inteligências individuais (DESCHAMPS; MOLINER, 2009, p. 101).

A partir desse conceito, Moscovici (2001) elaborou a teoria das representações sociais destacando, de um lado, a "diversidade de origem, tanto nos indivíduos quanto nos grupos" e de outro, a necessidade de enfatizar a comunicação "que permite aos sentimentos e aos indivíduos convergirem; de modo que algo individual pode tornar-se social ou vice-versa." (MOSCOVICI, 2001, p. 62).

Segundo Jodelet (2001), a importância das representações sociais se dá porque ninguém está 
isolado frente aos objetos num "vazio social". É necessário partilhar o mundo com as pessoas muitas vezes na busca de apoio e às vezes até pelo conflito, para conseguir "compreendê-lo, administrá-lo ou enfrentá-lo" (JODELET, 2001, p. 17). Para a autora, a representação social:

[...] é uma forma de conhecimento, socialmente elaborada e partilhada, com um objetivo prático, e que contribui para a construção de uma realidade comum a um conjunto social. Igualmente designada como saber de senso comum ou ainda saber ingênuo, natural, esta forma de conhecimento é diferenciada, entre outras, do conhecimento científico. Entretanto, é tida como um objeto de estudo tão legítimo quanto este devido à sua importância na vida social e à elucidação possibilitadora dos processos cognitivos e das interações sociais (JODELET, 2001, p. 22).

Trindade afirma que as representações sociais ocupam um importante espaço e são instrumento fundamental "para a compreensão da complexidade, das aparentes discrepâncias e dicotomias que surgem no processo de conhecimento de um dado fenômeno social, tendo como pressuposto o efeito do cotidiano em sua construção." (apud MARTINS; TRINDADE; ALMEIDA, 2003, p. 557).

Conforme afirma Mazzotti (2008), na atualidade somos submetidos a um grande fluxo diário de informações sendo, de alguma forma, afetados por elas. E buscamos compreender as coisas novas que surgem através da associação destas com algo que já seja de nosso conhecimento ou que faça parte do nosso cotidiano. Essa tentativa de compreensão das coisas se fortalece e se justifica pela necessidade de nos manifestarmos, fazermos julgamentos, procurarmos explicações ou nos posicionarmos sobre determinado objeto perante as pessoas no convívio social. A partir dessas interações são criados "universos consensuais" onde se produzem e se repassam novas representações que constituem as teorias do senso comum, designado pela autora como "construções esquemáticas que visam dar conta da complexidade do objeto, facilitar a comunicação e orientar condutas", além de fortalecer a identidade do grupo e proporcionar o "sentimento de pertencimento do indivíduo ao grupo.” (MAZZOTTI, 2008, p. 21).

A doença, como ameaça constante à vida, foi e continua sendo alvo das mais diversas representações sociais, do castigo à redenção, passando pela capacidade humana da reabilitação e da cura ou pela irrefutável constatação do inexplicável e do incurável. Herzlich (apud SEVALHO, 1993, p. 351) entende que "por ser um evento que modifica, às vezes irremediavelmente, nossa vida individual, nossa inserção social e, portanto, o equilíbrio coletivo, a doença engendra sempre uma necessidade de discurso, a necessidade de uma interpretação complexa e contínua da sociedade inteira", devendo-se, portanto, recorrer à história para analisar as concepções correntes em cada época e os fenômenos macrossociais e ideológicos envolvidos.

Nesse sentido, para Sevalho (1993, p. 353):

\begin{abstract}
A história das representações de saúde e doença foi sempre pautada pela inter-relação entre os corpos dos seres humanos e as coisas e os demais seres que os cercam. Elementos naturais e sobrenaturais habitam estas representações desde tempos imemoriais, provocando os sentidos e impregnando a cultura e os espíritos, os valores e as crenças dos povos. Sentimentos de culpa, medos, superstições, mistérios, envolvendo o fogo, o ar, a terra, os astros, a organização da natureza, estão indissoluvelmente ligados às expressões da doença, à ocorrência de epidemias, à dor, ao sofrimento, às impressões de desgaste físico e mental, à visão da deterioração dos corpos e à perspectiva da morte.
\end{abstract}

Laplantine (2010), a partir da observação de uma construção etiológico-terapêutica e metacultural dos discursos referentes à definição da doença nas sociedades e dando maior enfase na doença dita na primeira pessoa, ou seja, descrita e representada pelo olhar do doente, afirma que apesar das várias possibilidades de atribuição às causas das doenças e aos tipos de tratamento "a interpretação da doença e da cura, em seu próprio processo de elaboração, só 
tem à sua disposição um número limitado de termos" e cada modelo etiológico/terapêutico proposto por ele é organizado através de determinado número de relações entre estes termos que podem se opor, mas ao mesmo tempo se relacionam. "São as invariantes da experiência mórbida e da esperança de cura." (LAPLANTINE, 2010, p. 12).

Entre os modelos etiológicos apontados por esse antropólogo configuram-se os pares ontológico/ relacional, exógeno/endógeno, aditivo/subtrativo e maléfico/benéfico; e entre os modelos terapêuticos estão os pares alopático/homeopático, exorcista/ adorcista, aditivo/subtrativo e sedativo/excitante.

O modelo etiológico ontológico representa a doença como um "ser", uma entidade inimiga e estranha ao doente ("a coisa") em contraste com o seu par, o modelo relacional, que assume a doença como um desarranjo, um desequilíbrio, uma desarmonia por excesso ou por falta, mas não considerada como algo inimigo ou estranho. Também no modelo etiológico há a interpretação da doença como resultado da ação de elemento externo real ou simbólico (infecção microbiana, espírito patogênico, etc.) em oposição ao seu par, o modelo endógeno, que acredita que a doença seja advinda do interior do sujeito (temperamento, constituição, predisposições, caráter, hereditariedade). Ainda nesse modelo, Laplantine considera a visão subtrativa ou aditiva, sendo que a primeira toma a doença como resultado de algo a menos que deve ser restituído (anemia, emagrecimento, úlcera) e a segunda a vê como um "feitiço" lançado ao indivíduo ou como algo a mais que deve ser extraído (um tumor, uma febre, uma angústia). Considera, por fim, o discurso benéfico que associa a doença a uma mensagem a ser ouvida e desvendada, uma tentativa de restauração do equilíbrio perturbado ou como um episódio que exalta e enriquece, como graça, como sacrifício, salvação e libertação; e o seu oposto, o maléfico, que percebe a doença como nociva, perniciosa, indesejável, privadora e que deve ser combatida (LAPLANTINE, 2010).
O modelo terapêutico trata da representação da doença através das possíveis formas de tratamento, sendo então observados o alopático, que prevê a eliminação do sintoma pelo seu contrário com a ação do quimioterapêutico antagonista, e o homeopático, que crê na reativação dos sintomas pelas semelhanças e age para a cura no mesmo sentido da doença. O modelo exorcista admite a necessidade de extração da doença do corpo ou do espírito do cliente numa espécie de guerra contra a doença, em contraponto com a visão adorcista, que percebe a doença como um sacrifício do corpo, tendo-se o sagrado como doença e como cura. Também no modelo terapêutico, Laplantine sugere o subtrativo e o aditivo, resolutivos dos modelos etiológicos aditivo/subtrativo respectivamente, sendo então considerada a eliminação de líquidos ou extração de sólidos (purgativo, sangria, supressão de órgão) ou a ação que visa suprir uma falta (enxerto de um órgão, ingestão de vitaminas). Menciona, finalmente, o modelo sedativo/excitante, que visa o reequilíbrio do organismo pela inibição (estancar, acalmar, etc.) ou, contrariamente pelo estímulo do organismo ou da personalidade.

De acordo com as argumentações de Laplantine (2010), as representações sobre a doença se misturam e se engendram na articulação entre as variáveis possíveis e previstas dentro de um determinado modelo proposto; além disso, elas podem se modificar a partir do discurso médico sobre determinada doença, assim como este discurso médico também se modifica ao longo do tempo a partir da experiência empírica e da experiência afetiva da doença pelo doente e vivenciada pelo saber médico em uma interação social e não apenas biomédica.

Historicamente, doenças tidas como incuráveis e não compreendidas foram alvos de representações ambíguas e geraram preconceitos de ordem moral, justamente em face de seu mistério. Sontag, ao analisar as semelhanças entre a tuberculose e o câncer, considera que doenças furtivas e "ladras de vidas" passam a povoar a imaginação das pessoas 
e abrem caminho para as especulações leigas e médicas, como foi o caso da Aids no início da epidemia. Sontag considera que "qualquer doença encarada como um mistério e temida de modo muito agudo será tida moralmente, senão literalmente, contagiosa." (SONTAG, 1984, p. 12).

Podemos observar que, no caso da Aids, o mistério em relação à etiologia e à terapêutica nos anos iniciais de sua ocorrência, associado ao número crescente de casos que resultaram em mortes e à população inicialmente acometida pela doença (homossexuais, prostitutas, hemofílicos e usuários de drogas injetáveis), não só a caracterizaram como uma doença contagiosa como também instigou as teorias do senso comum, criando, assim, a estigmatização da doença, a identificação e segregação dos grupos de risco e o preconceito para com os doentes.

Conforme afirma Jeolás (2007, p. 31):

"A aids, ao acionar domínios de grandes investimentos imaginários - doença epidêmica, contágio, sexo, morte, paixão, drogas, entre outros -, torna-se temática privilegiada para reflexões sobre a importância do imaginário e do simbólico enquanto instâncias de apreensão da realidade."

Baseada em "aspectos obscuros" da manifestação da Aids, a sociedade passou a incutir aos infectados a responsabilidade e a culpa pela doença e a classificar determinados segmentos como "grupos de risco", formados por indivíduos que apresentavam um comportamento desviante, estando entre eles os homossexuais, os hemofílicos, os haitianos, os heroinômanos e as hookers (prostitutas).

Portanto, vale refletirmos de que forma as representações da década de 1980 recaíram sobre as pessoas afetadas ou vistas, à época, como predispostas (por pertencer aos então "grupos de risco") e criaram (e sustentaram) o estigma sobre a doença.

Segundo Jodelet (2001, p. 18), antes que a medicina elucidasse a natureza da Aids, explicações de senso comum foram elaboradas pelas pessoas à medida que a doença se estabelecia. Na interpretação moral e social "considera-se a Aids uma doença-punição que se abate sobre a licença sexual". A Aids é comparada à sífilis, "como efeito de uma sociedade permissiva, uma condenação pelas condutas degeneradas, uma punição pela irresponsabilidade sexual."

\begin{abstract}
Esta interpretação moral espontânea foi amplamente encorajada pelas instâncias religiosas. Pollack cita o exemplo do Brasil, onde a Conferência Nacional dos Bispos se levantou contra as campanhas governamentais de promoção do preservativo, qualificando a Aids de consequência da decadência moral, castigo de Deus ou vingança da natureza (JODELET; 2001, p. 18).
\end{abstract}

Segundo Murakami, Petrilli Filho e Telles Filho (2007), hoje, com o aumento da contaminação pelo vírus da Aids entre os heterossexuais, sobretudo entre as mulheres, e ainda com a tendência a maiores índices de contaminação entre as pessoas com pouca escolaridade e em municípios de médio e pequeno porte, emerge o conceito de vulnerabilidade. Este conceito é:

"[...] constructo e construtor de uma percepção ampliada e reflexiva, a qual identifica as razões últimas da epidemia bem como seus impactos, que vão das suscetibilidades orgânicas à maneira como são estruturados os programas de saúde, passando por aspectos comportamentais, culturais, econômicos e políticos". (MURAKAMI; PETRILLI FILHO; TELLES FILHO, 2007, p. 2).

Diante disto, cabe lembrarmos que os chamados "grupos de risco", tão referenciados no início da epidemia nos anos 1980, há muito já não se configuram como protagonistas da doença que se alastra entre as pessoas ditas "normais" nas quais, dentre outros, se identificam os segmentos juvenis. Tal fato fez cair por terra essa classificação, que passou a ser referenciada como comportamento individual de risco e vulnerabilidade social. 


\section{Análise dos Dados}

Participaram da pesquisa 91 jovens urbanos e 40 jovens rurais, num total de 131 jovens que representam $37 \%$ dos alunos do curso, com idades variando entre 14 e 20 anos.

Os participantes foram questionados sobre as cinco primeiras palavras que lhes vinham à cabeça ao ouvirem falar sobre Aids. Considerando a repetição de evocação de uma mesma palavra em relação ao número de participantes da pesquisa, as palavras mais evocadas entre os 40 participantes de origem rural foram: doença ou doença sexualmente transmissível (33), relação sexual ou sexo (21), camisinha ou preservativo (18), morte ou fatal (11), prevenção (8).

Entre os 91 alunos de origem urbana as palavras mais evocadas foram: doença ou doença sexualmente transmissível (63), relação sexual ou sexo (37), camisinha ou preservativo (34), morte ou fatal (40), preconceito (20), irresponsabilidade (15).

O resultado foi analisado em sete categorias de palavras de acordo com o que aludiam as respostas: sentimento, comportamento, lugar/ pessoa, consequência, tratamento, informação e transmissão.

Os dados demonstram que os jovens participantes da pesquisa associam com maior frequência a Aids aos comportamentos, à descrição da doença, às formas de transmissão e às suas consequências. Isto pode sugerir que há conhecimento por parte dos jovens sobre a doença, sobre os mecanismos de transmissão e sobre as dificuldades que podem ser encontradas pelos seus portadores, assim como também entendem que o comportamento individual pode determinar maior ou menor chance de contaminação.

Dentro da categoria "Comportamento" as palavras mais evocadas pelos jovens rurais foram camisinha ou preservativo (41\%), seguidas dos termos prevenção $(18,6 \%)$, preconceito $(16,2 \%)$ e falta de responsabilidade (13,9\%). Assim também pelos jovens urbanos as palavras mais evocadas foram camisinha ou preservativo $(25,7 \%)$, preconceito $(15 \%)$, irresponsabilidade $(11,3 \%)$.

Das 15 palavras classificadas na categoria "Consequência" entre os jovens rurais a mais evocada foi "morte" (73\%), sendo as demais palavras evocadas apenas uma vez. Das 67 palavras classificadas nessa mesma categoria entre os jovens urbanos a palavra morte também foi a mais evocada $(58,2 \%)$. Esses dados estão em consonância ao apresentado por Alves (2003) em sua pesquisa, realizada com homens rurais na faixa etária de 18 a 40 anos, na qual a representação predominante sobre a Aids associava-se à fatalidade e à morte. Discutiremos adiante esta associação.

$\mathrm{Na}$ categoria "Transmissão" as palavras mais evocadas foram "relação sexual", com $66 \%$ de evocação entre urbanos e $49 \%$ entre rurais. Isto pode se justificar pelas campanhas de prevenção da Aids veiculadas na mídia, com grande ênfase nas relações sexuais, principalmente aconselhando o uso da camisinha.

Não houve, entre os jovens de origem rural, palavras que indicassem a associação da doença aos homossexuais, hemofílicos, prostitutas e usuários de drogas e, entre os urbanos, apareceram apenas duas vezes as palavras "gay/homossexual" e "drogas" e apenas uma vez a palavra "prostituição". Este dado pode indicar que os jovens envolvidos nesta pesquisa, igualmente com o que acontece na esfera mundial, não associam mais prontamente a doença aos anteriormente chamados "grupos de risco". Todavia, embora estes "grupos" tenham sido pouco citados, esta pesquisa não permite avançar na discussão sobre a prevalência do preconceito entre os jovens e sobre o estigma da doença, dado que a ideia de perigo e de contágio atrelado a "férreas categorias de pensamento" (DOUGLAS, 1966) é claramente notável nos discursos.

Outra importante observação é que, tanto por parte dos jovens rurais quanto por parte dos 
jovens urbanos, não houve evocação de palavras que traduzissem as condições socioeconômicas e culturais associadas à Aids, o que nos leva a pensar que os jovens não conseguem perceber as questões sociais descritas por Parker (1994) e Szwarcwald et al. (2000) como condição de vulnerabilidade social e permanecem associando a culpa ao indivíduo, considerando apenas o risco individual, ou seja, o comportamento desviante em relação às normas sociais e ao "sagrado", conforme já descrito por Mary Douglas (1966). Um bom exemplo disso são as palavras carregadas de culpa e preconceito elencadas por um dos participantes, utilizando-se das inicias da sigla da doença:

Agora Idiota Durma Sozinho. (Entrevistado de 17 anos, sexo masculino, urbano, católico).

No entanto, Paiva et al. (2002) afirma que a partir da segunda década da epidemia as abordagens mais bem sucedidas para conter novos casos de infecção pelo HIV, assim como o adoecimento dos infectados, passaram a se inspirar nos princípios da promoção e proteção dos direitos individuais e sociais, propondo que a vulnerabilidade ao HIV e à Aids é tanto individual quanto coletiva.

Nesse sentido pudemos também observar que a palavra "falta" aparece com frequência de evocação pelos participantes rurais e urbanos fortalecendo a ideia de erro ou de carência: falta de responsabilidade, falta de prevenção, falta de cuidado, falta de preservativo, falta de sorte, falta de proteção, falta de conscientização, falta de precaução, falta de informação, falta de cura. Recorremos às palavras de Jeolás, ao afirmar que existem "significados de falta, culpa ou responsabilidade patentes em certas doenças" e "significados de pecado, doença ou anormalidade relacionados a algumas manifestações da sexualidade" (JEOLÁS, 2007, p. 42). Isto também se configura como um exemplo do modelo etiológico relacional proposto por Laplantine (2010), que considera a representação da doença como resultado do excesso ou da falta e que também reflete a interpretação religiosa da doença como punição por uma "falta com relação à ordem social" (LAPLANTINE, 2010, p 229). Assim, podemos inferir que essa representação metacultural concorra para a proximidade dos discursos entre os jovens rurais e urbanos com relação à Aids.

Observamos que não foram evocadas palavras que traduzissem "sintomas" da doença, exceto a palavra "dor" que se contextualiza muito mais no sentido de sofrimento emocional do que da dor propriamente física que pode se incluir entre os sintomas da síndrome. Talvez possa haver por parte da população estudada um desconhecimento dos sintomas da Aids.

Ao responderem a questão "O que é Aids para você?" observamos que a maioria dos jovens (91\% do total de participantes) classificam a Aids como uma "doença". Destes, 68,3\% (80 participantes) declaram ser uma "doença sexualmente transmissível". Entre os que responderam somente ser uma "doença", não associando-a ao sexo (31\% dos que a classificaram como doença), também não houve associação com as demais formas de transmissão e não houve uma definição sobre o significado da doença em si, mas apenas das consequências que ela traz (sofrimento, limites, privação).

Conforme mencionado anteriormente, a associação da Aids com a morte (17,5\% entre rurais e $18,6 \%$ entre urbanos) e com a ausência de cura $(17,5 \%$ entre rurais e $19,7 \%$ entre urbanos) também se configura como um dado importante contrastado com a pouca evocação da palavra prevenção (10\% entre rurais e 5,4\% entre urbanos). Isto nos leva a crer que os jovens temem a doença "fatal" (no sentido de ser mortal e de fatalidade, portanto, não prevenível), e estão, 
dessa forma, potencialmente vulneráveis. Uma jovem representou a Aids como:

\section{É um tipo de câncer que mata pouco a pouco e} acaba com a vida. (Entrevistada de 16 anos, sexo feminino, rural, católica).

Segundo Garcia, Bellini e Pavanello (2011), em um estudo das campanhas do HIV/Aids no Brasil, as primeiras campanhas de prevenção enfatizaram o medo ao associar a Aids à morte rápida com a intenção de estimular o uso do preservativo. Pudemos também, aqui, observar em alguns discursos a associação da doença como uma entidade amedrontadora, ameaçadora, "a coisa", que também reflete o modelo etiológicoantológico de definição metacultural das doenças apontado por Laplantine (2010):

Uma doença séria e grave, que põe medo em muita gente, uma coisa que eu nunca quero ter. (Entrevistado de 15 anos, sexo masculino, urbano, católico/espírita).

Garcia, Bellini e Pavanello (2011, p. 79) afirmam, ainda, que:

\begin{abstract}
A representação da Aids como morte imediata cria outro sentido: a sexualidade está próxima da morte. Sexo é uma prática mortal. Este primeiro momento das campanhas vinculou uma prática humana à efetiva culpa. Somos culpados pela nossa síndrome; somos culpados até pela nossa morte. Estávamos, então, lidando com uma perigosa argumentação: infecção é morte, logo sexo é morte. Aids, doença, saúde e sexualidade são dimensões entrelaçadas, nesse caso, com a ideia de morte e culpa.
\end{abstract}

Nove participantes não definiram a Aids como doença, porém observa-se que, apesar da ausência da palavra "doença" em alguns discursos que pretendem definir a Aids, as invariáveis históricas dos modelos propostos por
Laplantine aparecem constantemente nas respostas evidenciando situações de perda, morte, falta, excesso, descuido, câncer, consequência, etc., ficando clara a associação com a ideia da doença que vem transcendendo gerações em universos diferenciados.

Sobre as fontes de informação através das quais já ouviram falar de Aids, os jovens rurais fizeram maior referência à escola (98\%), seguida dos programas de TV (93\%), do posto de saúde (85\%) e de jornais e revistas (75\%). Entre os urbanos, os programas de TV e a escola apareceram em primeiro lugar com a mesma frequência como fonte de informação (97\%), seguidos dos jornais e revistas (82\%) e do posto de saúde (77\%). Observamos que não houve grande diferença nas fontes de informação destacadas pelos jovens rurais e urbanos, a não ser pelos sites da internet, sobretudo os sites de relacionamentos, quase não assinalados pelos jovens rurais.

Os programas de TV, um dos mais acessíveis meios de comunicação de massa, foram apontados com frequência pela maioria dos jovens. As campanhas governamentais de prevenção da Aids também foram bastante marcadas como fonte de informação tanto pelos jovens rurais quanto pelos urbanos, o que pode significar que elas, de uma forma geral, têm alcançado a juventude rural, já que sabemos não haver ainda campanhas governamentais específicas para esse público. A igreja configura-se igualmente como fonte de informação entre rurais e urbanos $(28 \%$ e $27 \%)$, respectivamente.

Um dado que consideramos relevante é que $10 \%$ dos jovens rurais e $12 \%$ dos jovens urbanos declararam conhecer alguém que contraiu o vírus. Este dado sugere a aproximação da doença que outrora era vista como algo distante, passando, aos poucos, a compor o cotidiano das pessoas, podendo até mesmo deixar de ser vista como doença do "outro" ou do outro grupo, conforme encontrado em pesquisa feita por Hélène Joffe ao 
afirmar que as pessoas dizem em primeiro lugar "eu não", "não o meu grupo" referindo-se à origem e disseminação da Aids (JOFFE; 1999, p. 300). A tendência a esta inversão pode ser traduzida pela opinião de dois participantes da pesquisa quando questionados sobre o risco de contrair a doença:

Sim. Porque como já aconteceu com alguém conhecido, a gente fica meio cismado, e como hoje está tão presente. (17 anos, sexo masculino, urbano, católico).

Sim. Porque está sendo algo um pouco comum nos dias atuais, e às vezes pode ocorrer de nós fugirmos dos métodos de se prevenir. (17 anos, sexo masculino, urbano, católico).

A maioria dos jovens (63\% rurais e $64 \%$ urbanos) admitiram o risco de contaminação. As justificativas foram variadas e implicam a condição de vulnerabilidade sentida pelos jovens, ora por forças externas às possibilidades de proteção elencadas por eles como a contaminação acidental, ora pela avaliação de suas atitudes "impróprias" à proteção e ora até mesmo pelo curso natural das coisas, já que é uma doença transmissível, e pela incerteza no futuro. Mais uma vez observamos que pode estar havendo uma diminuição da alteridade relegada à doença, muito embora uma porcentagem significante dos participantes tenha respondido "não" ao risco de contaminação.

Entre os que responderam "não" a esta questão (38\% dos jovens rurais e $36 \%$ dos jovens urbanos), várias justificativas dadas demonstram a situação de vulnerabilidade a que estão expostos frente a noções equivocadas sobre o assunto. Consideramos conveniente ressaltar que o indivíduo, ao se julgar consciente e protegido de algum mal, mas com noções equivocadas sobre como se proteger, poderá estar ainda mais vulnerável do que aquele que consegue perceber a sua própria vulnerabilidade. A confiança no parceiro também foi citada como fator de proteção e ausência de risco. Tal como observou Bretas et al. (2009, p. 7), "o fato de conhecer o parceiro elimina, em nível do imaginário, todos os riscos de se adquirir uma DST/Aids" sem pensar, o adolescente, que há um período de latência para o surgimento dos sintomas de uma doença e que esta pode ser imperceptível na relação sexual.

Estes dados também vão ao encontro da pesquisa realizada por Alves (2003), que afirma que os homens rurais envolvidos em sua pesquisa dispõem de um "conhecimento impreciso e inconsistente" e sentem-se distante do risco de se contaminarem, não se vendo como possíveis infectados, mas também não utilizando eficientemente as formas de proteção.

Muitos dos que responderam "não" são virgens e consideram a virgindade como um fator de proteção, projetando apenas no futuro a necessidade de utilização dos métodos de prevenção. Novamente a associação da Aids com as relações sexuais é notadamente mais marcante em relação aos demais meios de contaminação.

\section{Considerações Finais}

Muitas coisas estão em jogo quando nos propomos à abordagem do tema Aids com os jovens. A vergonha de falar sobre o assunto, o tabu em torno do sexo, as crenças, o medo de dizer o que sente e o constrangimento diante dos colegas. Ficou perceptível entre os jovens, durante a coleta de dados, a dificuldade de se expressarem, até mesmo através da escrita, o que pudemos perceber quando uns se esquivavam utilizando-se da expressão corporal, preocupados com que o colega não visse a sua resposta, ou quando pareciam querer saber o que o outro estava escrevendo como se buscando apoio e reafirmação para o que ele próprio escrevia, ou até mesmo quando riam e faziam pequenos comentários ao responder às questões e também ao se assegurarem do anonimato colocando o 
questionário embaixo dos outros já entregues. Porém isso nos diz de uma "verdade" escrita, ou seja, de algo que eles respondem, a nosso ver, com certa sinceridade (em relação a questões pessoais como, por exemplo, a virgindade e o número de parceiros), o que justifica o medo de serem "descobertos".

Este estudo limitou-se a analisar as representações a partir das declarações dos sujeitos. Porém, consideramos também, que pode haver diferença entre o "real" e o "ideal" buscado por eles, que justifique respostas tão semelhantes, homogeneizadas, repetidas, cerceadas pelas inteirações sociais e que apelam para uma análise detalhada dos discursos acompanhada de um estudo etnográfico que possa comprová-los (ou não).

Sabe-se que o acesso às principais ferramentas de comunicação como a televisão, o computador, o telefone celular, a escola, tem sido quase irrestrito ao meio rural e essas ferramentas parecem ser de uso frequente entre os jovens rurais que compuseram o espaço amostral da pesquisa, proporcionando a veiculação das mais diversas informações, dentre elas as informações sobre a Aids. Dessa forma, o jovem rural tem recebido informações sobre a Aids através dos mesmos dispositivos utilizados pelos jovens urbanos, o que pode ter resultado em posicionamentos bem parecidos entre eles quando questionados sobre a doença. Observamos a dificuldade de elaborações próprias, sendo muitas vezes utilizadas como recurso as frases prontas e estereotipadas.

Conclui-se deste estudo que os jovens consideram ter conhecimento sobre a Aids, porém percebe-se a condição de vulnerabilidade sentida e expressa por eles em suas respostas. Quando negam o risco de se contaminarem, demonstram estar ainda mais vulneráveis, o que fica claramente evidenciado em discursos equivocados com relação às formas de prevenção e contágio. Sobre este aspecto, também não conseguem perceber a vulnerabilidade social como fator concorrente à infecção pelo HIV. Concluímos que, isoladamente, a acessibilidade à informação, principalmente através da mídia, da escola ou das campanhas públicas esporádicas, não se mostra suficiente para mudar comportamentos, o que enseja ações sociais que possam convergir para uma abordagem mais próxima e menos impessoal para que o indivíduo, além de informado, seja afetado pela informação.

Concluímos também, na comparação entre as respostas de jovens rurais e urbanos, que em ambos permanecem incutidos os conceitos históricos sobre "doença", o que acreditamos colaborar para a proximidade dos discursos. Ao se referirem à Aids, demonstram em suas colocações que os mitos, as concepções religiosas e a ciência continuam se entrelaçando no campo do imaginário, gerando o "saber social" compartilhado por eles no convívio social que se intensifica a cada dia pela facilidade dos acessos.

É, portanto, a partir da construção do imaginário e deste convívio social no qual as representações circulam, que surgem as escolhas que projetarão o seu futuro. E, em relação à Aids, a menos que algo de extraordinário aconteça, tanto no sentido da descoberta da cura quanto na qualidade de um saber profícuo que seja capaz de provocar a mudança de comportamentos da juventude, o futuro estará sujeito às constantes do pensamento histórico sobre as doenças, às condutas individuais inadequadas e às “invariáveis" sociais que coloca os jovens, rurais ou urbanos, em contínua condição de vulnerabilidade.

\section{Referências}

ALVES, M. F. P. Sexualidade e prevenção de DST/ AIDS: representações sociais de homens rurais de um município da zona da mata pernambucana, Brasil. Cadernos de Saúde Pública, Rio de Janeiro, v. 19, sup. 2, p. S429-S439, 2003. Disponível em: $<$ http://www.scielo.br/pdf/csp/v19s2/a24v19s2. pdf $>$. Acesso em: 26 out. 2011.

BAUMAN, Z. Amor líquido: sobre a fragilidade dos laços humanos. Rio de Janeiro: Jorge Zahar, 2004. 
BRASIL. Ministério da Saúde. Diretrizes para implementação do projeto saúde e prevenção nas escolas. Brasília, 2006. Disponível em: <www. unicef.org/brazil/pt/SPE_Guia_Diretrizes.pdf> Acesso em: 10 out. 2010.

BRETAS, J. R. S. et al. Conhecimento sobre DST/AIDS por estudantes adolescentes. Revista da Escola de Enfermagem da USP, São Paulo, v. 43, n. 3, set. 2009. Disponível em: <http://www. scielo.br/pdf/reeusp/v43n3/a08v43n3.pdf $>$. Acesso em: 21 out. 2011.

CAMARGO, E. A. I; FERRARI, R. A. P. Adolescentes: conhecimentos sobre sexualidade antes e após a participação em oficinas de prevenção. Revista Ciência e Saúde Coletiva, Rio de Janeiro, v. 14, n. 3, maio/jun. 2009. Disponível em: <http://www.scielo.br/pdf/csc/ v14n3/30.pdf>. Acesso em: 20 out. 2011.

CARNEIRO, M. J. O ideal rurbano: campo e cidade no imaginário de jovens rurais. In: SILVA, F. C. T.; SANTOS, R.; COSTA, L. F. C. (Org.). Mundo rural e política: ensaios interdisciplinares. Rio de Janeiro: Campus, 1998. p. 97-117.

CASTRO, E. G. Juventude rural, "mais que uma palavra": uma problematização da construção de categorias sociais. In: MOREIRA, J. R.; BRUNO, R. L. (Org.). Interpretações, estudos rurais e política. Rio de Janeiro: Mauad X, 2010.

DESCHAMPS, J. C.; MOLINER, P. A identidade em psicologia social: dos processos identitários às representações sociais. Petrópolis: Vozes, 2009.

DOUGlaS, M. Pureza e perigo. São Paulo: Perspectiva, 1966.

GARCIA, M. L; BELLINI, M.; PAVANELLO, R. M. Análise retórica das campanhas sobre HIV/ AIDS no Brasil e em outros países. REMPEC - Revista Eletrônica Ensino, Saúde e Ambiente, Rio de Janeiro, v. 4, n. 1, p. 76-99, abr. 2011.

JEOLÁS, L. S. Risco e prazer: os jovens e o imaginário da AIDS. Londrina: EDUEL, 2007.
JODELET, D. Representações sociais: um domínio em expansão. In: . (Org.). As representações sociais. Rio de Janeiro: EDUERJ, 2001. p. 17-44.

JOFFE, H. "Eu não, “o meu grupo não": representações sociais transculturais da Aids. In: GUARESCHI, P. A.; JOVCHELOVITCH, S. (Org.). Textos em representações sociais. 5. ed. Petrópolis: Vozes, 1999.

LAPLANTINE, F. Antropologia da doença. 4. ed. São Paulo: WMF Martins Fontes, 2010.

MARTINS, P. O.; TRINDADE, A. Z.; ALMEIDA, A. M. O. O ter e o ser: representações sociais da adolescência entre adolescentes de inserção urbana e rural. Revista Psicologia: Reflexão e Crítica, Porto Alegre, v. 16, n. 3, p. 555-568, 2003. Disponível em: $<$ http://www.scielo.br/pdf/prc/v16n3/v16n3a14. pdf $>$. Acesso em: 26 out. 2011.

MAZZOTTI, A. J. A. Representações sociais: aspectos teóricos e aplicações à educação. Revista Múltiplas Leituras, São Paulo, v. 1, n. 1, p. 18-43, jan./jun. 2008.

MOSCOVICI, S. Das representações coletivas às representações sociais: elementos para uma história. In: JODELET, D. (Org.). As representações sociais. Rio de Janeiro: EDUERJ, 2001. p. 45-65.

MURAKAMI, J. K.; PETRILLI FILHO, J. F.; TELLES FILHO, P. C. P. Conversando sobre sexualidade, IST e AIDS com adolescentes pobres. Revista Latino-Americana de Enfermagem, Ribeirão Preto, v. 15, n. spe, out. 2007. Disponível em: <http://www.scielo.br/pdf/rlae/v15nspe/pt 22. pdf>. Acesso em: 13 ago. 2012.

PAIVA, V. et al. Capacitando profissionais e ativistas para avaliar projetos de prevenção do HIV e de Aids. Revista Saúde Pública, São Paulo, v. 36, n. 4, p. 4-5, ago. 2002. Disponível em: <www.scielo.br/pdf/rsp/ v36n4s0/11158.pdf>. Acesso em: 20 out. 2010.

PARKER, R. G. A construção da solidariedade: AIDS, sexualidade e política no Brasil. Rio de Janeiro: Relume-Dumará: ABIA,1994. 
SEVALHO, G. Representações sociais de saúde e doença. Cadernos de Saúde Pública, Rio de Janeiro, v. 9, n. 3, p. 349-363, jul./set. 1993. Disponível em: $<$ http://www.scielosp.org/pdf/csp/v9n3/22.pdf $>$. Acesso em: 20 ago. 2012.

SILVA, V. As flores do pequi: sexualidade e vida familiar entre jovens rurais. Campinas: Arte Escrita, 2007.

SOBARZO, O. O urbano e o rural em Henri Lefebvre. In: SPOSITO, M. E. B; WHITACKER, A. M. (Org.). Cidade e campo: relações e contradições entre urbano e rural. 2. ed. São Paulo: Expressão Popular, 2010.

SONTAG, S. A doença como metáfora. Rio de Janeiro: Graal, 1984.

SZWARCWALD, C. L. et al. A disseminação da epidemia da AIDS no Brasil, no período de 19871996: uma análise espacial. Cadernos de Saúde Pública, Rio de Janeiro, v. 16, supl. 1, jan. 2000.

VIEIRA, R. S. Juventude e sexualidade no contexto (escolar) de assentamentos do movimento dos trabalhadores rurais sem terra. Florianópolis: 2004. Disponível em: <http://www.bdae.org.br/ dspace/ bitstream/123456789/1644/1/tese.pdf $>$. Acesso em: 26 out. 2011.

WANDERLEY, M. N. B. O mundo rural como espaço de vida: reflexões sobre a propriedade da terra, agricultura familiar e ruralidade. Porto Alegre: Ed. UFRGS, 2009. 
